\title{
Kiwifruit (Actinidia deliciosa) propagation: Influence of stock plant sexuality on root development
}

\author{
L. Arfaei, M. Alizadeh* and H. Zarei \\ Horticulture Dep., Faculty of Plant Production, Gorgan University of Agricultural Sciences and Natural \\ Resources, Golestan, Gorgon, I.R. Iran \\ *Email: mahdializadeh@gau.ac.ir
}

Received : 08.04.2021 ; Revised: 16.06.2021; Accepted : 20.06.2021

\begin{abstract}
Kiwifruit (Actinidia chinensis) is a dioecious vine, commercially propagated through hard wood stem cuttings. To evaluate the effect of sexuality of donor plants on rooting of stem cuttings of kiwifruit and the effect of different concentrations of Indole butyric acid (IBA), a study was undertaken with factorial arrangement and completely randomized design including four commercial varieties and 6 replications. The IBA hormonal treatments were applied at four levels i.e. 0, 250, 500 and $1000 \mathrm{mg} / \mathrm{l}$. Three female varieties known as Abbott, Hayward, Hayward Behi and one male genotype (pollinizer) were evaluated. Morphological parameters including largest and smallest roots, root numbers, leaf area and rooting percentage of the stem cuttings were recorded during three months. The biochemical parameters such as total carbohydrates, phenols, chlorophylls and endogenous Indole-3-acetic acid (IAA) content of donor plants were also estimated. Analysis of variance showed that auxin treatment had positive effect at many parameters as compared to control. The parameters like smallest root length, root numbers and rooting percentage were positively affected by hormonal treatment. Application of IBA@500 mg/l showed maximum length $(0.766 \mathrm{~cm})$ and the highest number of roots (0.5). Among varieties, the Hayward and male genotype showed maximum root length as well as root numbers. Rooting percentage of male genotypes was found to be the highest $(28.35 \%)$ as compared to female varieties. Among hormonal treatments IBA $1000 \mathrm{mg} / \mathrm{l}$ led to highest percentage of rooting $(21.67 \%)$. The highest chlorophyll rate $(3.49 \mathrm{mg} / \mathrm{g})$ and greatest total sugar content $(0.011 \mathrm{mg} / \mathrm{g})$ were recorded in Abbott variety stock plants. The mean leaf area $\left(1501 \mathrm{~mm}^{2}\right)$ of stock plants was maximum in Hayward. The estimation of endogenous Indole Acetic Acid (IAA) by HPLC showed that the pollinizer (male) had maximum amount $(1.052 \mathrm{mg} / \mathrm{l})$ of this natural hormone. The correlation among traits revealed that a positive correlation between root numbers, rooting percentage and callus size with the content of endogenous IAA may be observed. The results definitely proved that the sexuality of mother plant has effective role in rooting and the male genotype has higher capacity to root development.
\end{abstract}

Keywords: Kiwifruit, propagation, IBA, IAA, Rooting, Sexuality

\section{INTRODUCTION}

The kiwifruit, often shortened to kiwi in many parts of the world (Actinidia deliciosa), is gaining popularity worldwide due to its rich nutritional, medicinal values with phytochemicals properties as it contents a lots of bioactivities, such as antitumor, anti-inflammatory, antioxidant, hypoglycemic, and hypolipidemic activities (Khan et al., 2019). The flowers are fragrant, dioecious or bisexual, borne singly or in triple in the leaf axils, are 5- to 6-petalled, white at first, changing to buffyellow, $2.5-5 \mathrm{~cm}$ broad, and both sexes have central tufts of many stamens though those of the female flowers with no viable pollen. The flowers also lack nectar. It flowers in November. Male and female flowers appear on different plants (dioecious) and both sexes have to be planted in close proximity for fruit set (Shastri et al., 2012). Currently $85 \%$ of the kiwifruit produced from Actinidia deliciosa and the remaining $15 \%$ of Actinidia chinensis (Ferguson, 1990).

The main kiwifruit female commercial cultivars are Abbott, Manti, Alison, Brono and male cultivars Matoa and Tomori. Italy is now the leading producer of kiwifruit in the world, followed by New Zealand, Chile, France, Greece, Japan and the United States (Shastri et al., 2012). Kiwifruit is usually propagated through cuttings. Though it can be propagated from seed but seedlings are not recommended because of its dioecious nature as the sex is unknown until flowers are produced. Propagation of kiwifruit with different types of stem cuttings such as hardwood, semi hardwood and soft wood cuttings have been successfully implemented, 
but the technique and rooting ability are different. However, IBA increased rooting of all three kinds of cuttings (Hartman et al., 2002). It is established fact that to harness the maximum efficiency from a crop cultivation, use of genuine planting material is the foremost requirement. Due to heterozygous nature of fruit crops, use of vegetatively propagated planting material is the scientific practices (Ghosh and Brea, 2015). Numerous factors such as genetic, environmental and chemical factors are involved in successful rooting of cuttings (Macdonald, 1993; Sweta, 2005). The IBA is the best and most popular commercial growth regulator to accelerate the rooting of cuttings (Hartman et al., 2002). Various methods of IBA application were already tried viz., direct use of powder, rapid dipping method and hormonal solution, however, the sexuality of mother plant and its impact of root initiation was not previously studied. The present research work was undertaken to ascertain the possibility of cutting propagation of four different varieties (three female varieties as compared to one male (pollinizer) genotype. Furthermore, the role of IBA pre-treatments and the IAA content of stock plants and its possible correlation with rooting capability of cuttings were studied.

\section{MATERIALS AND METHODS}

The present study was undertaken in Gorgan University of Agricultural Sciences and Natural Resources, Iran. The experiment was laid out as complete randomized design with six replications. Three female varieties known as Abbott, Hayward, Hayward Behi and one male genotype (pollinizer) were evaluated for their capacity to root development. Thirty hard wood cuttings from each variety as well as male genotype were procured from a commercial kiwifruit orchard in December. These were shortened to $25-30 \mathrm{~cm}$ (at least four nodes) and their basal parts were dipped in different concentrations of IBA $(0,250,500$ and $1000 \mathrm{ppm})$ for ten seconds prior to insertion in rooting substrates. These were then inserted in a temporary medium comprising perlite and sawdust (2:1) for three weeks in which bud sprouting was occurred. Due to utilization of mature canes as source of cuttings, the flower bunches also were produced on some sprouted new shoots those were also manually removed. The cuttings were then transferred to medium comprising washed sands under mist system (Fig. 1). Misting was scheduled for two minutes spray in every 40 minutes to maintain average relative humidity of greenhouse in $70 \% \pm 5$. Air temperature and light intensity fluctuation on the bench surface of greenhouse were $25-35^{\circ} \mathrm{C}$ and $11,000-14,000$ lux during mid-day, respectively. In order to prevent fungal infection a general recommended fungicide (Carbendazim, $0.2 \% \mathrm{w} / \mathrm{v}$ ) was also sprayed every 20 days on to the bench surface. Morphological parameters of rooted cuttings including root numbers, largest and smallest roots and rooting percentage were measured 90 days after inoculation. Furthermore, total sugars, mean leaf area and endogenous level of Indole-3-acetic acid (IAA) of donor plants were also measured. The amount of total sugars was estimated using anthrone reagent method (Thimmaiah, 2004). The High performance liquid chromatography (HPLC) was utilized for estimation of endogenous IAA. The IAA standard was dissolved in methanol (HPLC grade) in a range of $0-9 \mathrm{mg} / \mathrm{l}$. Reproducibility of the results was confirmed by the analysis of three injections per each sample. The retention time was recorded to be $7 \mathrm{~min}$ for both standard and samples. Analyses were performed in a HPLC unit (Merck-Hitachi, Germany-Japan) comprising a L-7100 HPLC pump equipped with a photodiode array L-2450 detector (Hitachi, Japan) and software EZ chrome. Separation was carried out using an Exsil C18 cartridge $(250 \times 4.6 \mathrm{~mm})$. The mobile phase was an isocratic of deionized water-acetonitrile ( $73 \%$, $26 \%$ respectively $(\mathrm{pH}=4))$ at a flow-rate of $1 \mathrm{ml} /$ min and the detection wavelength of $280 \mathrm{~nm}$. All samples were run in triplicate. The linearity range was determined from 1-9 mg/1 with a $20 \mu 1$ injection volume $(\mathrm{R} 2=0.997)$. Sample aliquots were filtered through a $0.20 \mu \mathrm{m}$ nylon membrane (ALBET ${ }^{\circledR}$ LabScience, Germany) prior to injection.

The data was analyzed using SAS software, based on completely randomized design with 6 replications. The mean comparison was performed with LSD test.

\section{RESULTS AND DISCUSSION}

In the present study, the exogenous IBA application had positive effect of adventitious root 
Table 1. Analysis of variance of measured rooting parameters of stem cuttings of four kiwifruit genotypes

\begin{tabular}{llccc}
\hline Sources of variation & df & Mean root length & No. of roots & Rooting percentage \\
\hline Treatment & 3 & $4.91^{*}$ & $1.57^{*}$ & $1262.34^{*}$ \\
Genotype & 3 & $28.93^{* *}$ & $23.47^{* *}$ & $114.61^{* *}$ \\
Genotype $\times$ treatment & 9 & $3.28^{\text {ns }}$ & $3.25^{\text {ns }}$ & $118.55^{\text {ns }}$ \\
Error & 64 & 2.68 & 2.27 & 5.54 \\
C.V. & - & 30.04 & 29.62 & 6.98
\end{tabular}

*significantly different $\mathrm{p}<0.05, * *$ : are significantly different $\mathrm{p}<0.01$; ns: non-significant

Table 2. The influence of IBA treatments and genotypes on rooting parameters of kiwifruit hardwood cuttings.

\begin{tabular}{lcccccccc}
\hline & \multicolumn{3}{c}{ IBA treatment $(\mathbf{m g} / \mathbf{l})$} & \multicolumn{3}{c}{ Kiwifruit cultivars } \\
\hline Trait/Treatment & 0 & 250 & 500 & 1000 & Abbot & Hayward & H. Behi & Male \\
Rooting (\%) & $15.85^{\mathrm{c}}$ & $12.51^{\mathrm{d}}$ & $16.68^{\mathrm{b}}$ & $21.67^{\mathrm{a}}$ & $0.84^{\mathrm{d}}$ & $25.01^{\mathrm{b}}$ & $12.51^{\mathrm{c}}$ & $28.35^{\mathrm{a}}$ \\
No. of roots & $0.441^{\mathrm{b}}$ & $0.440^{\mathrm{b}}$ & $0.500^{\mathrm{a}}$ & $0.683^{\mathrm{a}}$ & $0.008^{\mathrm{b}}$ & $0.816^{\mathrm{a}}$ & $0.291^{\mathrm{b}}$ & $0.95^{\mathrm{a}}$ \\
\hline
\end{tabular}

* Means in the same row followed by different letters are significantly different at $P<0.01$ using LSD-Test.

Table 3. : The average leaf area, total sugars and endogenous level of Indole Acetic Acid (IAA) measured in stock plants of different kiwifruit cultivars.

\begin{tabular}{lccc}
\hline cultivar & $\begin{array}{c}\text { Average leaf } \\
\text { areacm }^{2}\end{array}$ & $\begin{array}{c}\text { Total sugarsF.W. } \\
\mathbf{m g} / \mathbf{g}\end{array}$ & $\begin{array}{c}\text { Endogenous Indole } \\
\text { Acetic Acid (IAA) }^{\mathrm{a}}\end{array}$ \\
\hline Abbot & $1464^{\mathrm{b}}$ & $0.011^{\mathrm{a}}$ & $0.298^{\mathrm{d}}$ \\
Hayward & $1501^{\mathrm{a}}$ & $0.002^{\mathrm{b}}$ & $0.667^{\mathrm{c}}$ \\
Hayward Behi & $1292^{\mathrm{c}}$ & $0.0018^{\mathrm{b}}$ & $1.052^{\mathrm{b}}$ \\
Male & $1246^{\mathrm{d}}$ & $0.0018^{\mathrm{b}}$ & $1.398^{\mathrm{a}}$ \\
\hline
\end{tabular}

${ }^{*}$ Means in the same column followed by different letters are significantly different at $P<0.01$ using LSD-Test.

Table 4. The correlations among measured parameters of stock plants and cutting response.

\begin{tabular}{ccccccc}
\hline Rooting & No. of roots & Callus size & IAA & Leaf area & Total sugars & Traits \\
\hline & & & & - & 1 & Total sugars \\
& & & 1 & $0.486^{\text {ns }}$ & Leaf area \\
& & 1 & $-0.890^{* *}$ & $-0.789^{* *}$ & IAA \\
& 1 & $0.829^{* *}$ & $0.661^{*}$ & $-0.047^{*}$ & $-0.639^{*}$ & Callus size \\
1 & $0.992^{* *}$ & $0.372^{\text {ns }}$ & $0.711^{* *}$ & $-0.320^{\text {ns }}$ & $-0.761^{* *}$ & No. of roots \\
\hline
\end{tabular}

induction in kiwifruit hard wood stem cuttings. The analysis of variance of measured rooting parameters of stem cuttings of four kiwifruit genotypes is shown in Table 1. It is clear that the role of treatment and/or genotype is statistically significant. Among different concentrations, $1000 \mathrm{mg} / / 1 \mathrm{IBA}$ induced highest number of roots but it has no statistically significant difference with $500 \mathrm{mg} / \mathrm{l}$. The highest rooting percentage was also recorded in IBA 1000 $\mathrm{mg} / \mathrm{l}$ (Table 2). The role of auxin on root induction was already reported in numerous studies with different plant species (Hartman et al., 2002; Bartolini et al., 2008). Tanimotto (2005) in a critical review article, has stated the classical views of rootgrowth regulation by auxin and gibberellin

The results clearly demonstrated that male genotype has superior ability to induce adventitious roots. The male genotype had highest rooting 

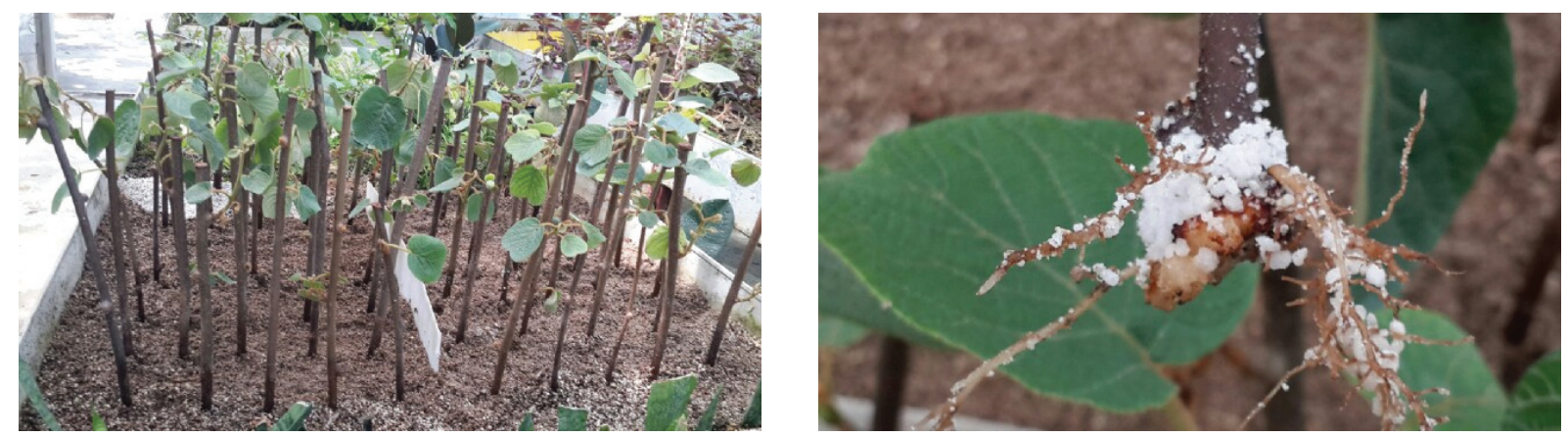

Fig 1: The kiwifruit hardwood cuttings under mist system 4 weeks after planting (left), root emergence on a stem cutting treated with $1000 \mathrm{mg} / \mathrm{l}$ IBA two months after planting (right).

percentage as well as number of roots as compared to three female varieties (Table 2). The effect of genotype on rooting have been reported by other researchers in different plant species. For example, during research on the effect of genotype on micropropagation of walnut trees, rooting between the two genotypes was observed differed that one reason was the plant hormone levels and peroxidase activity (Scaltsoyiannes et al., 1998). The male kiwifruits are more vigorous than female vines. As they do not produce fruit, the photosynthates are utilized for their vegetative growth. Furthermore, in the present study, the estimation of endogenous level of IAA by HPLC revealed that the pollinizer (male) genotype had significantly higher concentration $(1.052 \mathrm{mg} / \mathrm{l})$ of this natural hormone. The endogenous IAA level estimated in male vines, showed statistically significant difference as compared with other three female varieties (Table 3 ). It may be stated that such IAA level was definitely effective in root development on cuttings procured from mother plants. The role of endogenous Auxins on root formation was already reviewed by Blakesley et al. (1991). It has already reported that Auxin can be synthesized in young leaves and cotyledons (Ljung et al. 2001). The same long-distance pathway that carries carbohydrates from "source" to "sink" also facilitates the bulk flow of auxin and other hormones such as ABA and cytokinins as well as mRNA and proteins (Robert and Friml, 2009). So, it was not unusual that cuttings prepared from this genotype had maximum rooting percentage. The correlation data (Table 4) also clearly showed that the endogenous IAA was positively correlated with rooting percentage. The Abbott donor plant had lowest concentration of IAA and it could be one of the reasons for poor root ability of cuttings prepared from this variety (Table 2).

The correlations among measured parameters of stock plants and their cutting response have been shown in Table 4. In the present study, the rooting parameters were recorded 90 days after inoculation. However, the cutting basal ends form callus tissues just 3 weeks following inoculation. The callus tissue formation had significant positive correlation with number of roots. The endogenous level of IAA was also positively and statistically correlated with rooting percentage and number of roots.

According the results, it may be concluded that IBA treatment had really positive effect on adventitious root induction on kiwifruit hardwood cuttings. The stem cuttings treated with $1000 \mathrm{mg} / 1$ IBA showed maximum root length and rooting percentage (Fig 1). Hence, the same treatment may be suggested for commercial nurseries involved in kiwifruit propagation. On the other hand, the results showed that male vines would have higher rooting potential as compared to female ones. Furthermore, the endogenous IAA content of male stocks was significantly higher than female varieties and this parameter was positively correlated with rooting parameters.

\section{REFERENCES :}

Blakesley, D., Weston, G.D. and Hall, J.F. 1991. The role of endogenous auxin in root initiation. Plant Growth Regul., 10: 341-353.

Bartolini, G., Petruccelli, R.A., Pestelli, P., Bernardi, R. and Durante M. 2008. Preliminary study on in vivo rooting of two olea europaea L. genotypes. Acta Hort., 791:191-196. 
Ferguson, A.R. 1990. The Genus Actinidia. In: Warrrington, I.J and G.C. Weston (eds.) kiwi fruit: Science and Management. Richards Publisher, Auckland PP. 15-35

Ghosh, S. N. and Bera, B. 2015. Studies on standardization of propagation methods of some minor fruit crops in India. International Journal of Minor Fruits, Medicinal and Aromatic Plants, 1(1): 31-36.

Hartman, H. T., Kester. D. E., Davis, F. T. and Genev, R. L. 2002. Plant Propagation, Principles and Practices.7th Edn. Prentice Hall, Englewood Cliffs, New Jersey, U.S.A.

Khan Muhammad Saeed, Li-Jun You, Chun Chen, Zhen-Gang Zhao, Xiong Fu and Rui Hai Liu. 2019. Comparative assessment of phytochemical profiles and antioxidant and antiproliferative activities of kiwifruit (Actinidia deliciosa) cultivars. Journal of Food Biochemistry, 43(11). https://doi.org/ 10.1111/jfbc. 13025

Ljung K, Hull A.K., Celenza J., Yamada M., Estelle M., Normanly J. and Sandberg G. 2005. Sites and regulation of auxin biosynthesis in Arabidopsis roots. Plant Cell, 17:1090-1104.

Macdonald, B. 1993. Practical Woody plant propagation for nursery growers. TimblerPress. Portland, Oregon, Vol. 1, 670p.

Robert, H.S. and Friml, J. 2009. Auxin and other signals on the move in plants. Nat. Chem. Biol., 5:325-332.
Scaltsoyiannes, A., Tsoulpha, P., Panetsos, K. P., and Moulalis, D. 1998. Effect of genotype on micropropagation of walnut trees (Juglans regia). Silvae Genetica, 46: 326-331.

Shastri, K. Bhatia, V. R Parikh, P and Chaphekar, V. 2012. Actinidia deliciosa: A review. International Journal Pharmaceutical Sciences and Research, 3 (10):3543-3549.

Swetha. H. 2005. Propagation of Indian Levender (Bursera delpechiana Poiss.Ex Engl.) thorugh cutting under Mist. M. Sc. Thesis. India: College of Agriculture Dharward, University of Agricultural Sciences Dharward, Department of Horticulture, India. Tanimotto, E. 2005. Regulation of Root Growth by Plant Hormones-Roles for auxin and gibberellin. Critical Rev. Plant Sci., 24(4). https://doi.org/10.1080/07352680500196108

Thimmaiah, S.R. 2004. Standard methods of biochemical analysis. Kalyani Publishers, New Delhi, India. 